\title{
Reflexiones sobre el viaje de Francisco de Miranda al Imperio Otomano
}

\author{
Mehmet Necati Kutlu* \\ Ankara Üniversitesi (Turkiye) \\ Reflections about Francisco de Miranda's travel to the Ottoman \\ Empire
}

\begin{abstract}
RESUMEN
Francisco de Miranda, en sus viajes por Europa, permanció casi tres meses en el Imperio Otomano (en Esmirna y

Estambul). En sus escritos, el político venezolano se refirió especialmente a la vida social y cultural, a la economía y al ejército y a la defensa de Turquía. Por ello, el conocimiento de primera mano de estos aspectos parece la motivación fundamental de su estancia, sin que sea posible señalar ninguna gestión en busca de apoyo a la causa de la independencia
\end{abstract} americana.

\section{PALABRAS CLAVE:} Francisco de Miranda / Imperio Otomano / Viaje / Siglo XVIII

\begin{abstract}
Francisco de Miranda, in his travels across Europe, visited for almost three months the Ottoman Empire (Izmir and Istambul). In his writings, the Venezuelan politician dealt especially with social and cultural life, the economy and the army and defence of the country. This is why the first-hand knowledge of these aspects seems to be the main reason of his stay; instead, it is not possible to find any step in the search of support for the American independence.
\end{abstract}

\section{KEYWORDS:}

Francisco de Miranda / Ottoman Empire / Travel / $18^{\text {th }}$ Century

En este trabajo intentaremos poner de relieve el itinerario de Francisco de Miranda en tierras otomanas y trataremos de exponer algunas ideas acerca de sus finalidades. Francisco de Miranda dedicó cuatro años de su vida, entre 1785 y 1789, a viajar por Europa, y en algunos países por los que pasó, encontró apoyo para la causa de la liberación hispanoamericana. Los apuntes muy detallados que tomó Miranda a lo largo de estos viajes, junto a otros elementos de su archivo personal, se editaron

* Profesor Titular, Universidad de Ankara (Turquía), Facultad de Lenguas, Historia y Geografía, Departamento de Lengua y Literatura Españolas (Ankara Üniversitesi. Dil ve Tarih-Cografrya Fakültasi. Bati Dilleri ve Edebiyatlari Bölümü Ispanyol Dili ve Edebiyati Anabi lim Dali. 06100 Sihhiye-Ankara). E-mail: kutlu@ humanity.ankara.edu.tr 
por la Presidencia de la República de Venezuela bajo el título de Colombeia1, habiéndose editado, hasta el presente, veinte tomos, a la espera de completar la serie.

En el contexto de estos viajes, Francisco de Miranda llegó a las tierras del Imperio Otomano pasando de la isla de $Z_{\text {Zante }}^{2}$ a Patras $^{3}$, que es un puerto importante de la hogaña Grecia en las costas Mediterráneas, al sur del país. A pesar de ello, nosotros nos limitaremos a retomar las memorias de Miranda que tienen que ver con las actuales tierras de Turquía, omitiendo la parte entre Patras y el Mar Egeo.

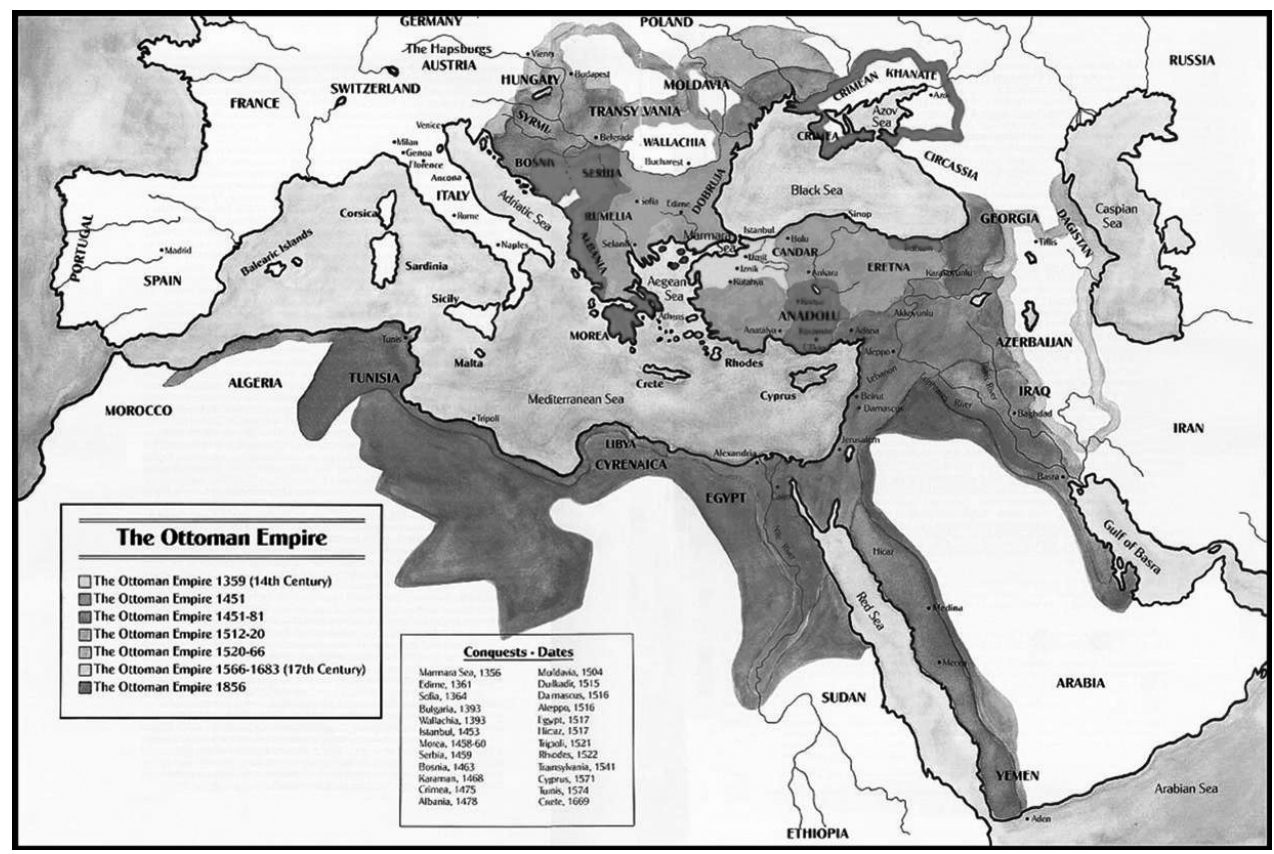

Fig. 1. Mapa del Imperio Otomano

Francisco de Miranda llega a lo que es la Turquía de hoy el 3 de julio de 1786 por vía marítima, y el primer puerto que toca es el puerto de Esmirna, hoy lzmir. Se queda en Esmirna hasta el 12 de julio de 1786, día en que se embarca en una nave turca para ir hacia Estambul. Su estadía en Estambul dura del 30 de julio al 23 de septiembre del mismo año.

El primer punto a considerarse en el contexto de este viaje de Francisco de Miranda, es, sin duda, el motivo que lo llevó a realizar tal odisea. Una de las ra-

1 MIRANDA, Francisco de: Colombeia, Ediciones de la Presidencia de la República, Caracas, 1981.

2 Zante es el nombre con que se conoce comúnmente la isla de Zakyntos, la más septentrional de las islas jónicas.

${ }^{3}$ Ciudad en el Golfo homónimo del Mar Jónico en el sudoeste de la Grecia de hoy, entre las penínsulas Balcanica y el Peleponeso. 
zones aducidas indudablemente era el hecho de buscar apoyo a la causa de la independencia hispanoamericana. El mismo Miranda manifiesta, según López Egea, que las razones principales de este viaje eran «adquisición de experiencia y conocimientos para completar su educación» ${ }^{4}$. Por otra parte, también podría decirse que el Generalísimo había pasado por Turquía simplemente porque el camino a Rusia lo había obligado a pasar por aquí. Sin embargo, el mismo contenido de las memorias revela la posibilidad de la existencia de alguna otra motivación, además de las previamente manifestadas. En efecto, no sería sorprendente que un buen observador y analista como Miranda hubiera obtenido algo más que un único beneficio de unos viajes tan largos y agotadores. Partiendo de esta evaluación y considerando que muchos de los países visitados tenían conflictos entre sí, podemos deducir que Miranda podría haber valorado los conocimientos adquiridos después de clasificarlos cuidadosamente. Esto podría haberse hecho por el Precursor para facilitar la gestión de cualquier apoyo o ayuda para la causa hispanoamericana en los países a los que había viajado. Esta hipótesis fue insinuada anteriormente por el ilustre investigador Alfonso Rumazo González, quién escribió lo siguiente acerca del particular: «Miranda, invitado por el embajador sueco Heidestam, pasa las seis semanas que ha prefijado para el estudio de la sociedad, economía y política turcas [...] Hay algo que capta y analiza muy cuidadosamente Miranda: las relaciones de Turquía con Rusia, había obtenido la Crimea y el Kuban, pero no todo estaba terminado entre las dos naciones; la guerra volverá» ${ }^{5}$.

Nuestro propósito en el contexto de este estudio es precisamente exponer este tema e intentar ver si hay posibilidad de encontrar algunos datos que puedan guiarnos a considerar si podría haber una motivación oculta, al margen de lo más aparente, en el viaje de Miranda al Imperio Otomano. De lo contrario, nos atendríamos a la idea aceptada de que el viaje del Precursor a Asia Menor era una mera visita obligatoria, que se había visto forzado a venir por este camino para pasar de Europa a Rusia.

Los escritos de Francisco de Miranda en relación a sus memorias sobre Turquía se pueden agrupar bajo tres titulares generales que serían los siguientes:

a) Aquellos relacionados con la vida social y cultural del país.

b) Aquellos que reúnen datos y comentarios sobre la economía.

c) Aquellos relacionados con la defensa, el ejército y el armamento del país.

En una parte de estos apuntes, el Precursor sobresale como viajero y escritor, pero en otras partes del diario llaman la atención sus grandes capacidades como investigador y analista. Precisamente los escritos en los cuales el Precursor so-

\footnotetext{
4 EGEA LÓPEZ, Antonio: El Pensamiento Filosófico y Político de Francisco de Miranda, Academia Nacional de la Historia, Caracas, 1983, p. 82.

5 RUMAZO GONZÁLEZ, Alfonso: Ocho Grandes Biografías, Ediciones de la Presidencia de la República, Caracas, 1993, pp. 109-110.
} 
bresale como investigador y analista son los que queremos subrayar en esta intervención.

En la época en que Francisco de Miranda realizó su viaje al Imperio Otomano, éste se encontraba bajo el mando del Sultán Abdülhamit I, y pasaba por una etapa bastante crucial. El historiador e investigador chileno Paulino Toledo describe aquellos años del Imperio de la manera siguiente:

«Miranda llega a Estambul en tiempos de Abdülhamit I, en momentos que el imperio se encontraba gozando de un interregno de paz de cerca de seis años. De los 15 años del reinado de Abdülhamit I, casi 10 pasaron en guerra, sea con Rusia, Irán o Austria. En 1774 el Imperio deberá afrontar la derrota de la Batalla de Kozluca, que tuvo lugar en las cercanías de Varna, en Bulgaria, ante las tropas rusas. La paz de Kutchuk Kainardji (Küçük Kaynarca) pondrá fin a seis años de prolongadas guerras, pero originará nuevos problemas en Crimea.

La paz de Kutchuk Kainardji convenció a Abdulhamit de la necesidad de una reforma de carácter militar, por ello incentivó especialmente las innovaciones puestas en práctica por el ingeniero militar francés, de orígen húngaro, general Baron de Tott, que estuvo al servicio de La Puerta hasta 1776. Asimismo impulsó la reestructuración y reconstrucción de la escuadra turca que había sido destruida por los rusos en el desastre de Çesme, el 7 de julio de 1770. Para ello contrató técnicos e ingenieros navales ingleses y franceses con el fin de construir buques conforme el sistema aplicado en Francia e Inglaterra. Todo este proceso es narrado en el Diario de Miranda como producto de sus visitas a los arsenales turcos y sus conversaciones con los marinos franceses ${ }^{6}$.

Las dos etapas de guerra entre Rusia y el Imperio Otomano durante el reinado de Catalina II (1768-1774 y 1787-1791) favorecieron a Rusia, cambiando la distribución de poderes en el Mar Negro. Las dos guerras habían sido desatadas por iniciativa del Imperio Otomano bajo el efecto de las provocaciones de la diplomacia europea, pero habían terminado con la victoria de los rusos. Como resultado de estas guerras, Crimea, incluyendo toda la península homónima y sus tierras al norte, cayó en manos de Rusia que, gracias a esta nueva situación, empezó a disfrutar de una vasta fachada marítima sobre el Mar Negro ${ }^{7}$.

Bajo la luz de esta información, vale la pena recordar que Francisco de Miranda había estado en las tierras del Imperio Otomano en los meses de verano de 1786, y había partido hacia Rusia en el mes de septiembre después de abandonar el territorio turco. A la sazón existían múltiples conflictos entre Rusia y el Imperio Otomano y estaba a punto de estallar la citada guerra del año 1787. Se había perdido la península de Crimea ante el avance de las tropas rusas al mando del celebre general Grigori Alexandrovich Potemkin (1739-1791), el mismo militar que también se encontraría encabezando las tropas rusas durante la segunda guerra

6 TOLEDO MANSILLA, Paulino: Descripciones Hispanoamericanas de Estambul en el Imperio Otomano, Embajada de Chile en Turquía, Ankara, 2004, p. 20.

7 KAZGAN, Gülten y ULÇENKO, Natalya: Dünden Bugüne Türkiye ve Rusya (Turquía y Rusia del Pasado al Presente), Istanbul Bilgi Üniversitesi Yayınları, Estambul, 2003, p. 27. 
ruso-turca (1787-1789). Recuérdese que este militar y su soberana Catalina II fueron los más cercanos protectores del Precursor durante su estadía en Rusia. Menos de un año después de que Miranda pasara por Estambul, el 17 de agosto del año 1787, el Gran Visir (Primer Ministro) del Imperio Otomano Yusuf Pacha y el Seyhülislam, es decir el Director de Asuntos Religiosos del Estado, se reunirían con el embajador ruso Bulgakoff ${ }^{8} y$, exigiéndole la "devolución» de Crimea entre otras condiciones, harían la declaración oficial de guerra. Un detalle al que se había referido Miranda en su diario sobre el trato que en el Imperio se hacía a los embajadores extranjeros, también se cumpliría en aquellos días ${ }^{9}$. Justo después de la declaración de guerra, el embajador ruso quedaría arrestado con todo su séquito y encarcelado en los calabozos de Yedikule ${ }^{10}$.

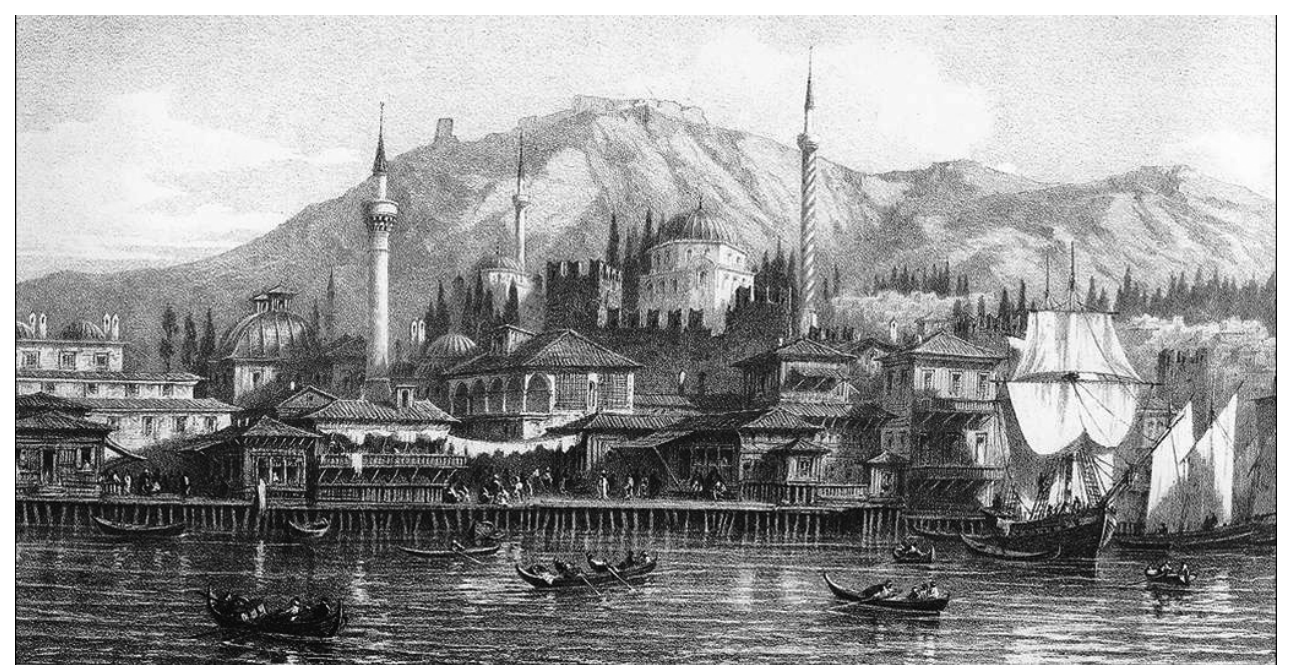

Fig. 2. Esmirna

En los días que pasa en Esmirna, Miranda intenta conocer los aspectos sociales y culturales de la urbe, entra en contacto con los diplomáticos y comerciantes europeos e intenta acumular la máxima información comercial posible. No se olvida de ver los principales puntos de interés turístico, intenta reflejar el carácter multicultural y multinacional de la ciudad, pero inexplicablemente no visita la legendaria ciudad de Efeso ${ }^{11}$, que queda apenas a cien kilómetros al sur de Esmirna.

8 Francisco de Miranda conoce al Embajador Boulgakoff (él escribe su nombre de esta manera) el día 15 de agosto de 1786 en casa del comerciante holandés Van Der Schroeff ubicada en la pradera de Büyükdere y anota que tuvo una larga conversación con el (Ibidem, p. 430).

9 MIRANDA, Francisco de: Colombeia ..., p. 405.

10 Yedikule (Siete Torres) es la denominación dada a un sector de las murallas de Estambul que en distintas etapas imperiales se utilizó como calabozo. Miranda divisa este sector el primer día que llega a Estambul, desde el buque en que se encontraba.

${ }_{11}$ Histórica ciudad de Asia Menor a orillas del Mar Egeo que llegó a ser la capital de la provincia romana de Asia. 
En lo relacionado a sus observaciones estratégicas, Miranda empieza a hacer observaciones y comentarios de este carácter justo al entrar al Golfo de Esmirna, al divisar un pequeño castillo y calificarlo como «pobre cosa»12. La segunda observación interesante que hace (esta vez sobre la economía de la urbe) es el importante papel que juegan los marineros hydriotas ${ }^{13}$, a quienes considera «los mejores navegantes del Imperio Turco», explicando que dichos marineros prácticamente dominan todo el transporte marítimo de la zona. Hay que tener en cuenta que Esmirna fue el principal puerto de comercio exterior en el siglo XVIII. Las estadísticas de la época revelan que en el año 1784, el 32\% de la exportación de todo el Imperio se realizaba a través del puerto de Esmirna, y esta cifra prácticamente no difería en cuanto a la importación ${ }^{14}$.

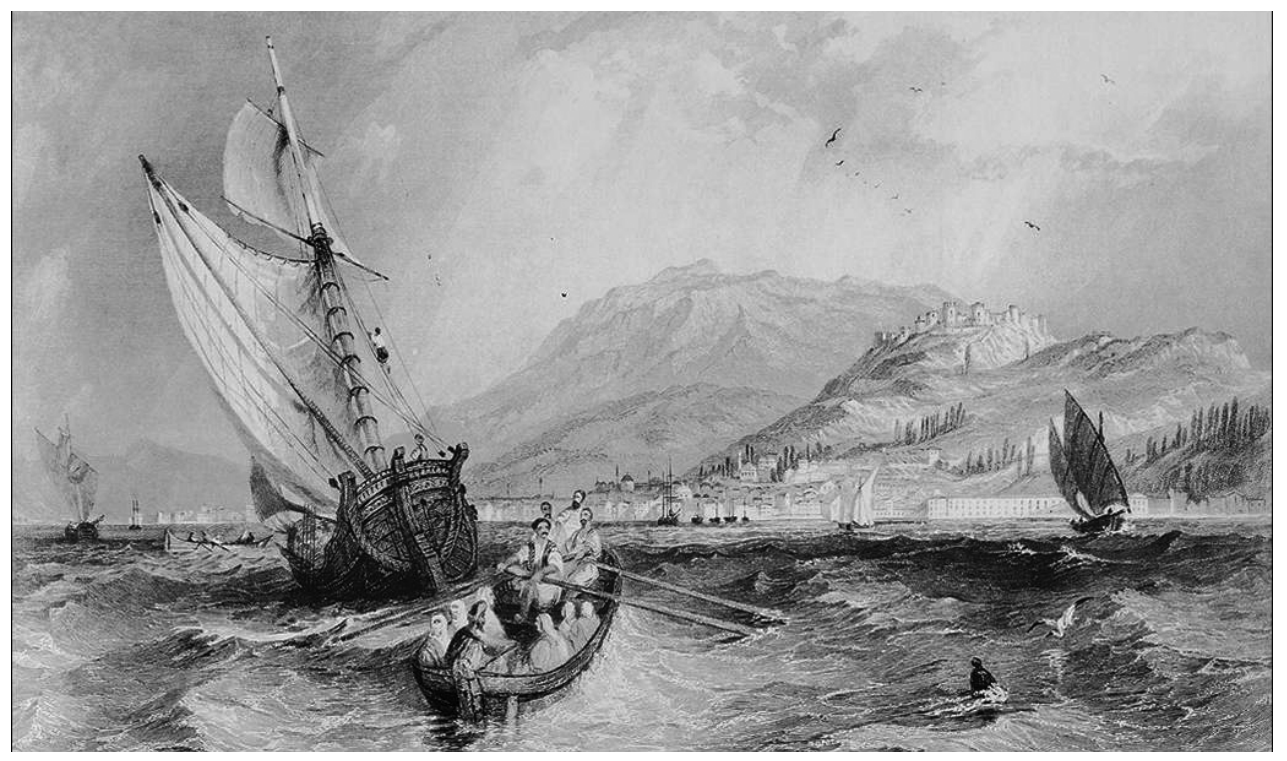

Fig. 3. Esmirna

El día 10 de julio de 1786, Miranda continúa anotando sus observaciones militares y comerciales, al visitar la fortaleza de la ciudad con algunos amigos ingleses, a quienes conoce desde Inglaterra. Anota que el importante puerto de la ciudad se encuentra bajo influencia de los franceses, ya que éstos controlaban la mitad del monto total del comercio. Entrando ya en detalles, anota que anualmente se importaban 20.000 balas de paño desde el puerto de Marsella.

\footnotetext{
12 MIRANDA, Francisco de: Colombeia ..., p. 393.

${ }^{13}$ Hydra (o Idra) es una pequeña isla de $50 \mathrm{~km}^{2}$, que durante la dominación otomana vivía del transporte marítimo. Hoy la isla pertenece a Grecia y es un centro turístico.

14 KÜÇÜKKALAY, Mesut: Osmanlı Ithalatı (La Importación Otomana), Kitap Yayınevi, Estambul, 2007, p. 33.
} 
je, y el buque entra en el Mar de Mármara, pasando inevitablemente por el estrecho de Dardanelos. El Precursor contempla las ruinas de Sestos (Gelibolu) y Abidos (Çanakkale, Bogazhisar) y recuerda la leyenda de Hero y Leandro ${ }^{17}$, observa cuidadosamente los castillos y opina que ni los antiguos ni los nuevos castillos que se encuentran protegiendo la entrada serían capaces de detener a cualquier escuadra importante que intentara pasar, si no fuera por la corriente que modera el avance, facilitando el trabajo de los artilleros ${ }^{18}$. Luego intenta ver las ruinas de la legendaria Troya mediante sus binoculares pero no las logra divisar. Son los días más calurosos del año, el buque fondea cerca de la costa para abastecerse de agua, y Miranda anota que cerca de Galipoli envían un bote a traer agua, "ya que los turcos y los negros beben más que el demonio ${ }^{19}$.

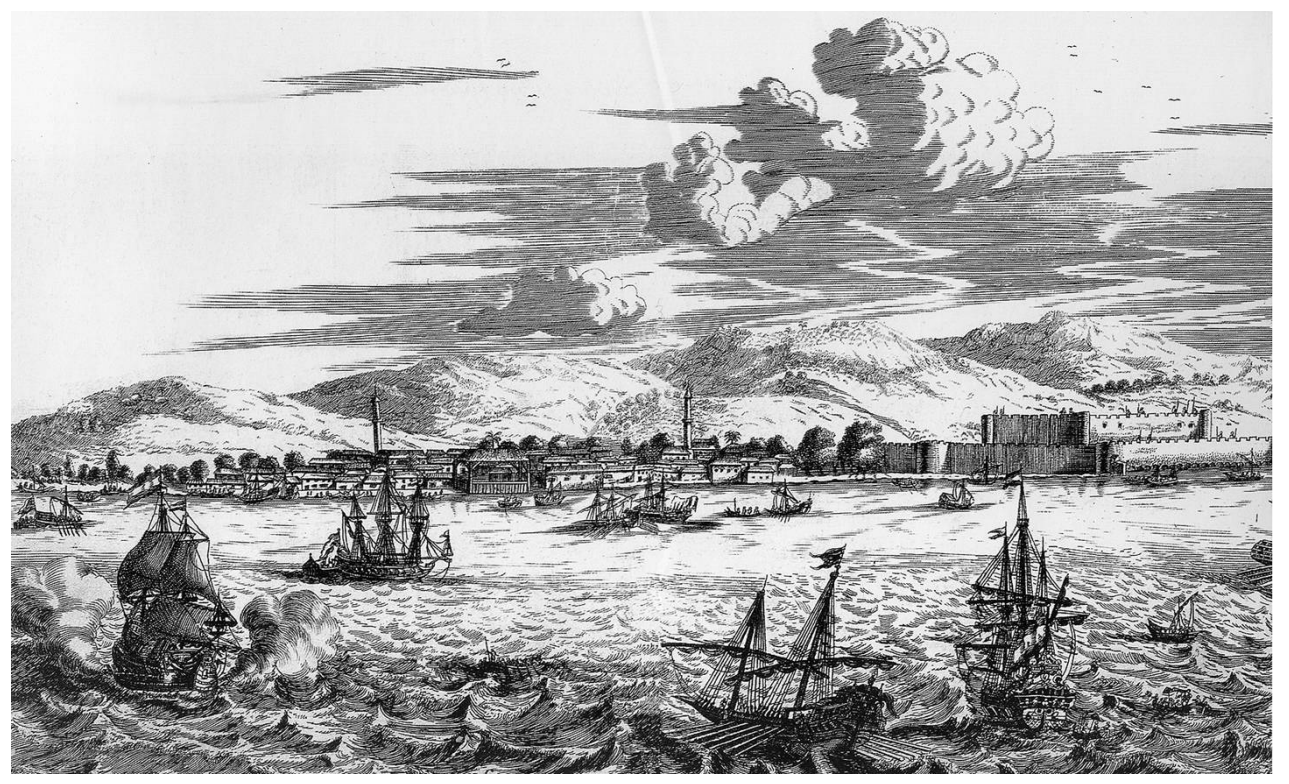

Fig. 5. Abydos

La nave en que se encuentra el ilustrado e ilustre viajero entra finalmente en el Bósforo el 30 de julio de 1786. Las principales actividades de Francisco de Miranda en Estambul, fuera de las que realizó para recopilar información comercial y militar, consistieron en visitas a lugares de interes turístico, encuentros con el cuerpo diplomático y algunas observaciones bastante interesantes relacionadas con la

17 Según la leyenda, Hero era una sacerdotisa de Afrodita que vivía en una torre en Sestos, en el extremo del Helesponto. Leandro era un joven de Abidos que quedaba en el otro lado del estrecho. Los jóvenes se enamoraron y Leandro empezó a cruzar el Helesponto a nado cada noche para estar con su amante. Hero debía encender una lámpara cada noche en lo alto de la torre para guiar a Leandro, pero una noche el viento apaga la lámpara y Leandro muere sin poder encontrar su dirección en el mar.

18 MIRANDA, Francisco de: Colombeia ..., p. 402-403.

19 MIRANDA, Francisco de: Colombeia ..., p. 404. 


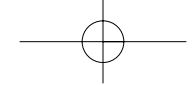

Reflexiones sobre el viaje de Francisco de Miranda al Imperio otomano

vida social de la metrópoli. En cuanto a las actividades de observación que pudieran ser interpretadas como de información de carácter militar, en caso de que fuéramos a admitirlas como tales, no sería erróneo decir que estaban bien trazadas y estaban ejercidas con bastante eficacia.

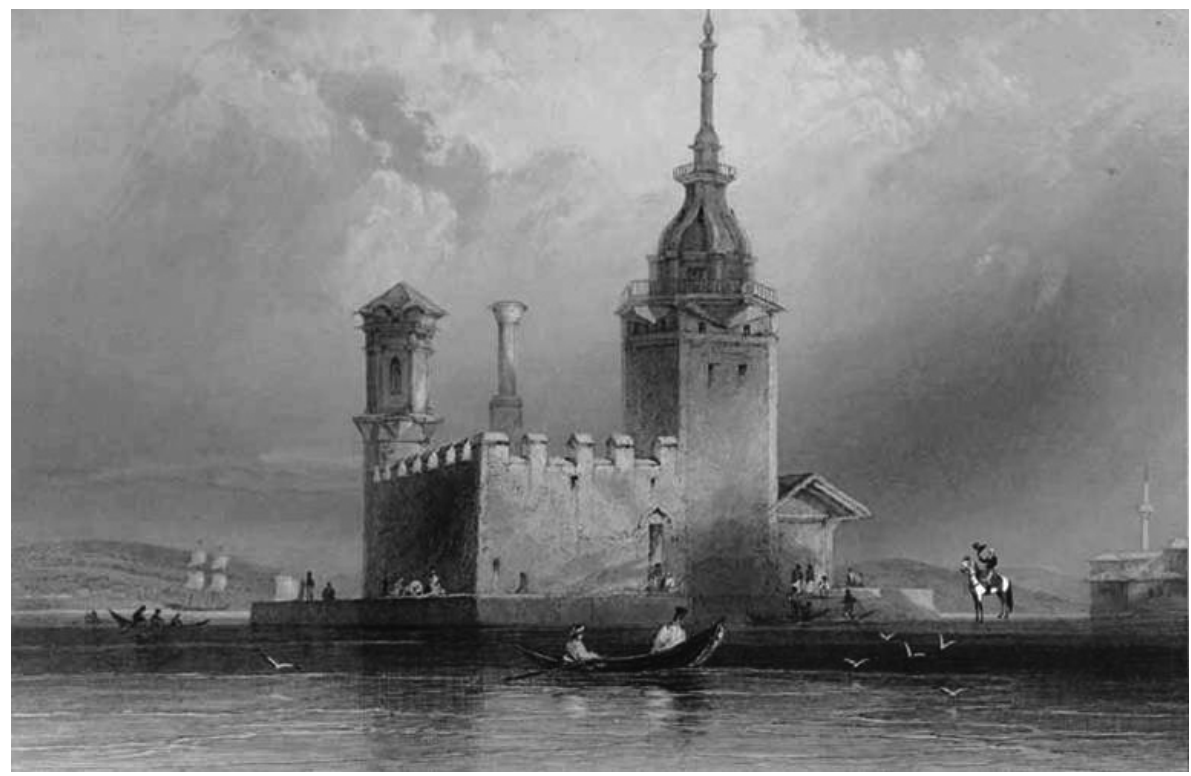

Fig. 6. El Bósforo y la Torre de Leandro

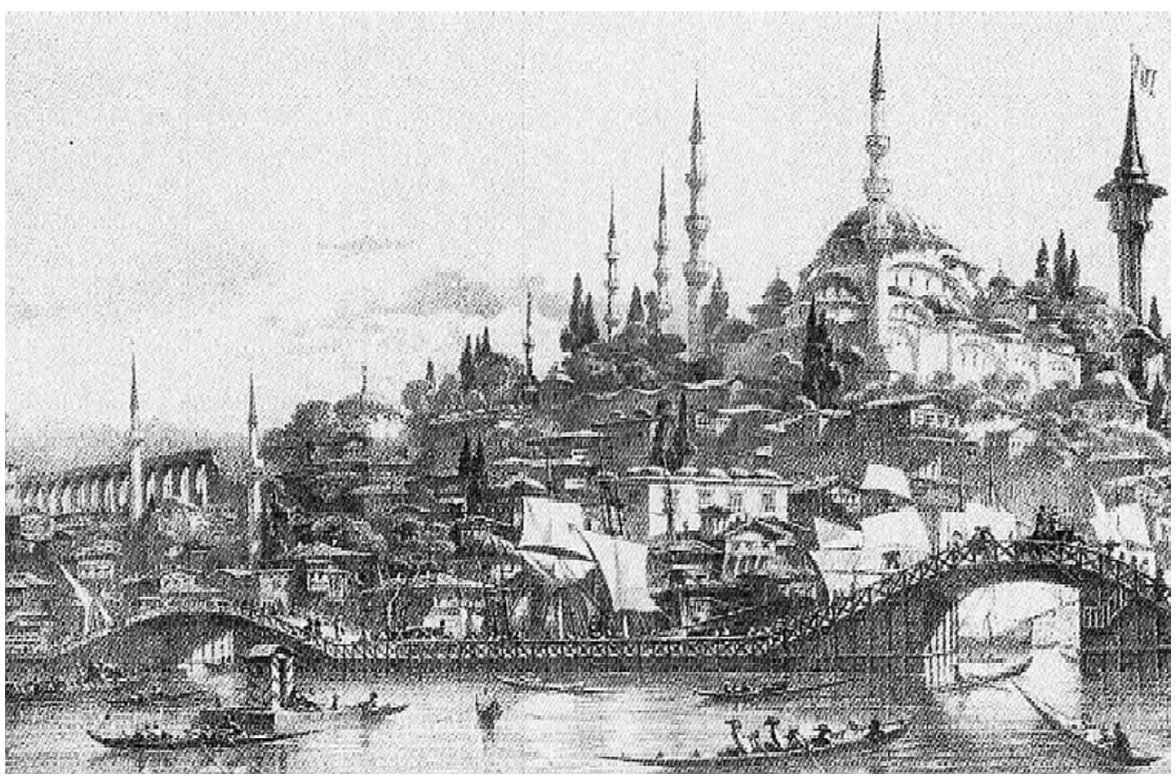

Fig. 7. Estambul

(C) UNED. Espacio, Tiempo y Forma 
Los principales ámbitos de interés del Precursor en Estambul, tal como lo señaláramos arriba, fueron aquellos relacionados con la economía de la capital otomana y las principales unidades de la marina y artillería turca. Antes, cabe señalar la gran impresión que le causara su llegada a la urbe. Miranda llega al puerto de Estambul el dia 30 de julio de 1786 y describe impresiones de la manera siguiente:

«No se puede seguramente dar una cabal idea del grupo bello y grandiosísimo que desde el mar presenta la ciudad de Constantinopla, Escutari, Calcedonia, Canal, Galatá, Pera, con sus principales mezquitas, minaretes y árboles que por todas partes se interpolan. Luego la belleza y extensión del puerto; la multitud de caiques o góndolas que continuamente pasan de una parte a otra, de Europa a Asia; los jardines y serrallo del Sultán, sus kioscos a la orilla del mar...»²0.

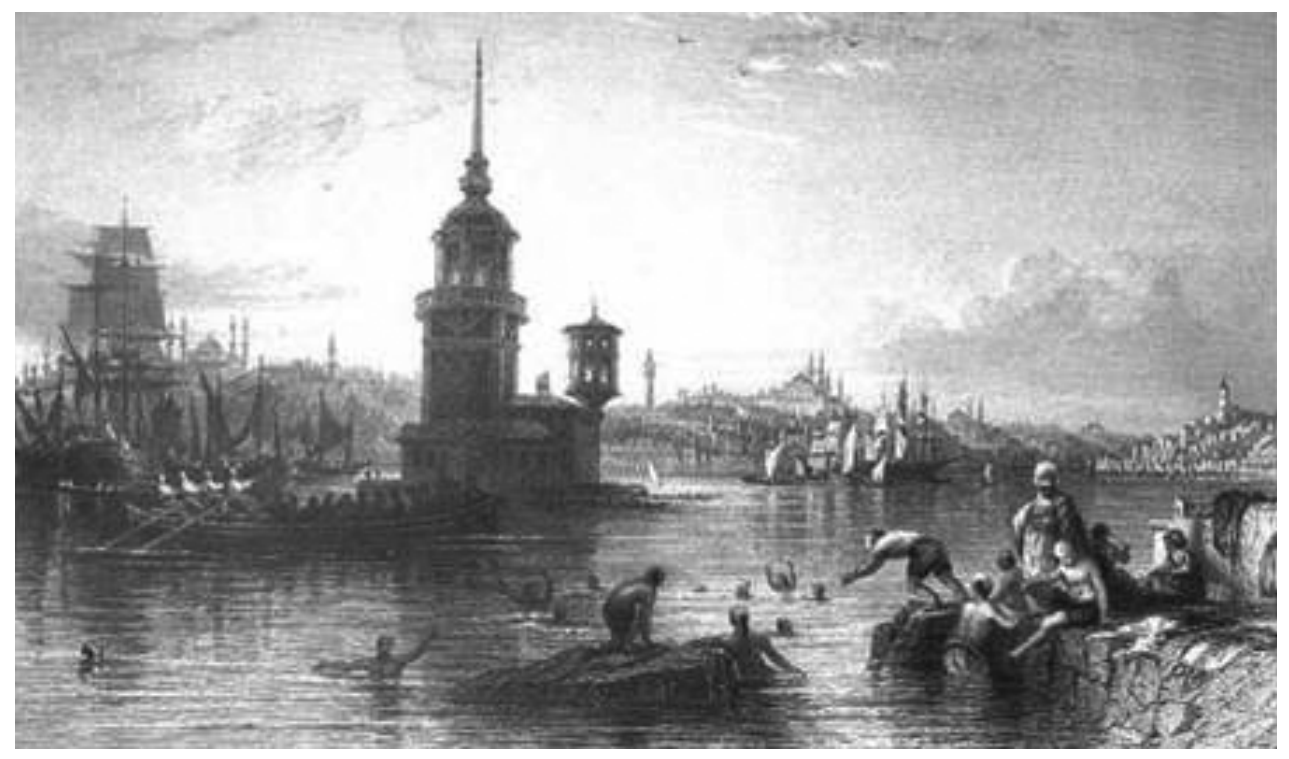

Fig. 8. El Bósforo y la Torre de Leandro

Miranda pasa los primeros días en la capital otomana instalándose y tratando de conocer a los que serían sus buenos contactos en la ciudad, y la verdad es que logra establecer tales amistades con sorprendente rapidez. En este contexto se entrevista con el enviado español, pero no llegan a entablar buenas relaciones, y prefiere continuar sus contactos con los representantes de los demás países europeos. El conocido historiador venezolano Tomás Polanco Alcántara anota lo siguiente acerca de esta pecuilaridad especial de Miranda y sus razones:

«Muestran los esquemas normales de reacciones humanas que algo tuvo que haber en su personalidad que motivaba ese respeto inmediato. Creo que puede

20 MIRANDA, Francisco de: Colombeia ..., p. 405. 
afirmarse que la causa de ese respeto era el enorme y extraordinario mundo cultural que reflejaba y que sólo es posible en las grandes personalidades. Por eso puede hablar de la evolución del castellano con Catalina, de tácticas militares con Wellington, de delicados problemas políticos con Mádison, de complejas cuestiones bibliográficas con Jefferson. Es el hombre que en la conversación recurre a la cita oportuna de Cervantes o de la Biblia, que transcribe en griego o en latín a los clásicos, que refleja en sus planes militares las ideas de los maestros del arte de la guerra. El interlocutor lo capta enseguida y desde ese momento Miranda tiene abiertas las puertas de su respeto y hasta de su afecto ${ }^{21}$.

Todos están de acuerdo en que Francisco de Miranda era un hombre muy exepcional en lo relacionado con su bagaje cultural y su capacidad intelectual; ésto junto a su inteligencia extraordinaria debió de influir positivamente en su aceptación en todos los países por él visitados. Sin embargo, la aceptación de Miranda, por lo menos en los círculos con que se conectó en Turquía no se puede basar tan sólo en estas cualidades del Precursor. Las famosas cartas de recomendación que solía llevar consigo podrían ayudarnos a comprender algo más, pero pienso que también se quedarían cortas para explicar el cuidadosísimo trato que recibe el ilustre caraqueño. En nuestra opinión, el entorno enciclopedista de la corriente de la Ilustración al que pertenecía Miranda, tenía obviamente sus representantes y seguidores en el Imperio otomano como en todas partes, y tales entornos habrían jugado el papel determinante en la aceptación inmediata del Precursor en las ciudades turcas.

Volviendo a nuestras observaciones sobre las memorias de Miranda, cabe decir que en lo tocante a temas socio-culturales no difieren en gran medida de los anotados por otros viajeros y escritores occidentales. Se mencionan las mezquitas, el Bósforo y su belleza impresionante, las obras arqueológicas de la ciudad, etc. Pero un punto al que se refiere es bastante interesante, ya que revela la actitud adoptada por el Sultán ante una catástrofe. Se trata de un incendio. Los terremotos e incendios fueron los dos principales motivos de destrucción en Estambul a lo largo de los siglos. Los incendios provocados a finales del siglo XVIII eran muy típicos en la ciudad, ya que era el modo de demostrar el descontento contra la administración autócrata y autoritaria del soberano. Sobre este tema, relata Miranda el día 9 de agosto de 1786 lo siguiente:

«Esta mañana se gritó fuego a cosa de las diez y prosiguió con furia a las inmediaciones del Palacio de Venecia y de Francia, hasta eso de las cinco de la tarde que se logró atajar, habiendo quemado al parecer más de 150 casas. ¡Oh, qué horror, a la verdad, y qué miseria ver las pobres gentes salvarse, abandonando sus casas y cuanto en ellas tienen de más precioso! El Gran Señor acudió inmediatamente -acude siempre- en persona. Se coloca en una casa inmediata a la parte por donde el fuego está más vivo, para que sus guardias y demás gentes esforzándose en preservar aquella casa, atajen el fuego más pronto. Mas cuando pro-

21 POLANCO ALCÁNTARA, Tomás: «Don Francisco de Miranda, una semblanza esquemática», en Venezuela 2001, Ministerio de Relaciones Exteriores, Caracas, Octubre, 2001, pp. (la cita en p. 38). 
sigue, sale y entra en otra. Vino desde la casa de campo sobre el Canal donde está ahora, en su gran Falúa. Le hizo salva el navío español que está en el puerto y concluído, se retiró inmediatamente ${ }^{22}$.

Sorprende hasta en Turquía que esta actitud adoptada por el soberano no sea un detalle muy conocido por los historiadores turcos, y la primera vez que se mencionó en el Congreso Imagen Mundial del Turco, organizado por la Universidad de Bahçesehir en Estambul en el mes de mayo de $2004^{23}$, llamó la atención de los académicos otomanistas presentes ${ }^{24}$.

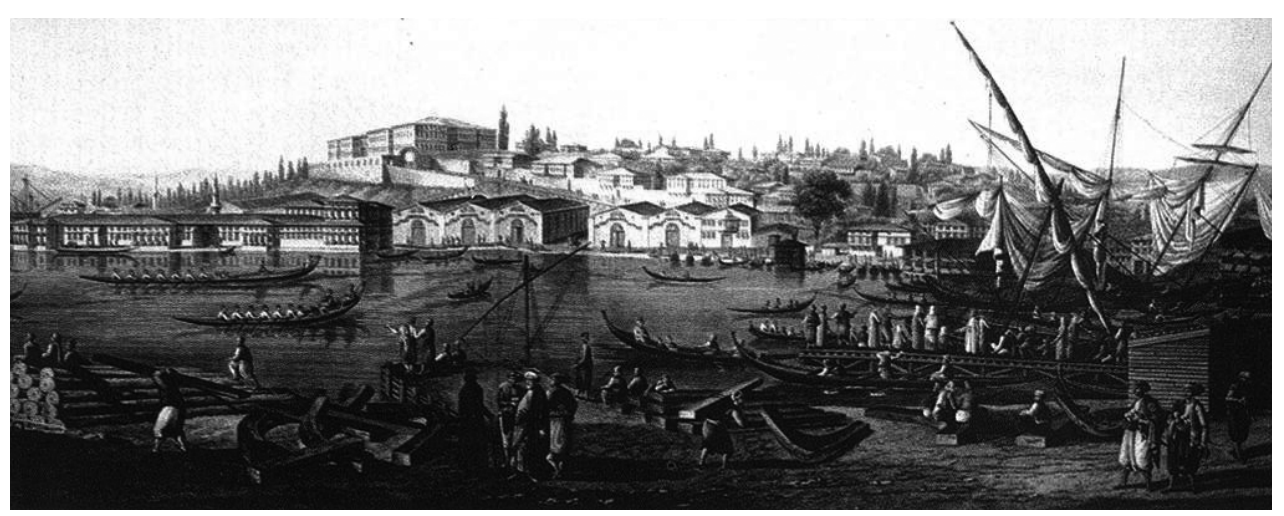

Fig. 9. Astillero en el Cuerno de Oro

En lo tocante a las actividades de observación militar en Estambul, Miranda concentra su atención en las unidades de artillería y marina. Gracias a los especialistas franceses que se encontraban asesorando la marina y los astilleros, el viajero tiene oportunidad de visitar casi todas las instalaciones estratégicas de la capital imperial y de tomar nota de lo que ve. O si queremos utilizar la forma de expresion del propio Miranda, pasa sus dias «en observaciones»25.

${ }^{22}$ MIRANDA, Francisco de: Colombeia ..., p. 420.

${ }^{23}$ NECATI KUTLU, Mehmet: Francisco de Miranda'nın Seyahatnamesi ‘Colombeia'da Türkiye ve Türkler (Turquía y los Turcos en la Crónica 'Colombeía' de Francisco de Miranda), Bahçesehir Üniversitesi I. Uluslararası Tarih Sempozyumu: 'Dünyada Türk Imajı', 13-14 Mayıs 2004, Dünyada Türk Imgesi, Kitap Yayınevi, Estambul, 2005.

${ }^{24}$ Una primera traducción parcial de las memorias del General Francisco de Miranda durante su estancia en el Imperio Otomano se hizo por el eminente diplomático y escritor turco Fuad Carım, editándose el libro por la imprenta Berksoy en 1965: CARIM, Fuat: Venezuelalı General Miranda'nın Türkiye'ye Dair Hatıratı, Yazar ve Seyyah Jean Chardin'in Anlattıgi Kalp Para Ticareti, Comte de Césy: Dördüncü Murad Tarafından Atanan Fransa Elçisi, Berksoy Matbaası, Estambul, 1965. No fue hasta el año de 2004 cuando las memorias turcas de Miranda fueron traducidas integramente al turco por iniciativa de la Embajada de la República Bolivariana en Turquía, misión encabezada por el ilustre académico y diplomático venezolano Dr. Kaldone G. Nweihed, siendo el traductor el autor de este trabajo: Venezuelalı General Miranda'nın Türkiye Anıları (Çeviren: Mehmet Necati Kutlu), Türkiye'deki venezuela Bolivar Cumhuriyeti BüyükelçiligiYayınları, Ankara, 2004.

${ }^{25}$ Miranda inicia los escritos de los dias 21, 22, 23, 24, 30, 31 de agosto de 1786 con estas mismas palabras. 
La atención que dedica Miranda a la milicia en Estambul se puede considerar bastante completa, ya que empieza mostrando su interés por las instalaciones militares justo al entrar a Estambul por barco. Al pasar el buque por el muelle coronado por la famosa construcción denominada Yedikule (las Siete Torres), que es parte de las murallas de la ciudad, anota unos comentarios que intercambia con el capitán del navío, prosiguiendo sus descripciones de la manera siguiente:

«Temprano comenzamos a bordear en demanda de Estambul, que ya veíamos cerca, y efectivamente a las 8 a.m. estábamos ya sobre esta inmensa ciudad. Viendo el castillo de las siete torres. Mi capitán tuvo buen cuidado de explicarme cómo ponían allí a los embajadores francos cuando se declaraba una guerra o no se comportaban bien ${ }^{26}$.

Ha de recordarse que el buen amigo de Miranda, el embajador Yakov Ivanovich Bulgakoff de Rusia, correría la misma suerte el año siguiente al estallar la guerra turco-rusa.

Miranda continúa su profundo análisis sobre la situación militar del país, visitando el entorno de los astilleros y el nuevo cuartel de la Marina el dia 3 de agosto de 1786. Después de hacer una descripción detallada de las instalaciones, anota que son protegidas por cañones de tipo Gribeauval, preparados por el ingeniero francés Saint-Remy. Miranda continúa sus observaciones de la manera siguiente:

"Con la asistencia de los de los señores Le Roy y Du Reste, ingenieros de la marina francesa, que nos acompañaron, vimos todo. Un navío de 74 , de construcción francesa, se está trabajando por éstos y asimismo varias corbetas de 14 cañones que deben servirles de cañoneras llevando un cañon de 36 a la proa, en imitación de nuestras lanchas cañoneras, pues los turcos están tan pagados de esta invención que han querido absolutamente que se construyan ${ }^{27}$.

El día 10 de agosto, Francisco de Miranda sale con el mencionado ingeniero francés Saint-Remy a ver los ejercicios de la escuela práctica de artillería. Al pasar por el arsenal escribe: «Está perfectamente abierto y sin resguardo alguno por la parte del mar» ${ }^{28}$. Y continúa relatando lo visto en la práctica de artillería de la forma siguiente:

«Aquí hay una batería de morteros con malos ajustes, la cual tiró algunas bombas con pasable buena dirección; otra con algunas piezas de a doce, sobre malísimas cureñas de ruedas paneladas y pésimas explanadas. Dos 'coronades' [carronadas] inglesas y más adelante la artillería de batallones que hacía fuego según el método europeo con pasable prontitud [...] más con dos graves defectos: primero que el blanco estaba elevado sobre una montaña a más de cincuenta varas sobre el horizonte y que sólo el primer tiro va apuntado. El resto sigue según la dirección en que queda la pieza al retroceder»29.

\footnotetext{
26 MIRANDA, Francisco de: Colombeia ..., p. 405.

27 MIRANDA, Francisco de: Colombeia ..., p. 411.

28 MIRANDA, Francisco de: Colombeia ..., p. 421.

29 MIRANDA, Francisco de: Colombeia ..., pp. 421-422.
} 
El detalle más curioso y representativo de esta interpretación estratégica de la misión de Miranda en el Imperio Otomano sale a la luz el dia 8 de septiembre del mismo año, cuando el mismo «Precursor» anota el propósito y destinatario final de sus observaciones, que expone después de unas descripciones bastante importantes de la Armada otomana de la época con las siguientes afirmaciones:

«La escuadra actual se compone de 20 navíos desde 50 a 75 cañones, 12 fragatas y 30 embarcaciones pequeñas como cutters, bombardas, lanchas cañoneras, etc. Mas tienen el gran defecto de construir con maderas verdes y así, al cabo de seis u ocho años están ya inútiles dichas embarcaciones. Véase el estado adjunto que está hecho por el mismo ingeniero constructor, el señor Le Roy (lo presté a Mr. Pitt en Londres y lo he perdido así)»30.

Estas lineas de Miranda en nuestra opinión constituyen un curioso documento sobre un acto de aparente entrega de información estratégica. El mencionado Mr. Pitt es nada menos que el Primer Ministro británico William Pitt el Joven (1759-1806), cuyas relaciones con Miranda oscilaban entre apoyo y silencio, bienvenidas y largos periodos de ignorar al venezolano, de modo que si no hubiera sido por la secretaria/sobrina del Primer Ministro, Lady Esther Stanhope, no habrían sido tan fructíferas.

Francisco de Miranda abandona las tierras otomanas el día 23 de septiembre de 1786, "después de haber visto las mezquitas, la catedral de Santa Sofía, la famosa biblioteca de Rashid Pacha [sic] y otros lugares notables da la capital turca». Miranda marcha por vía marítima a Jerson, puerta meridional de la Rusia de Catalina II (hoy en Ucrania). En su portafolio de color verde, que siempre llevaba consigo, además de la carta de recomendación para el príncipe Viazemski, guarda otras para el general Raninski, para el cónsul austriaco, Rozorovic, para el negociante holandés van Shutern y otros. En la frontera, Miranda, como todos los viajeros, tiene que pasar la cuarentena, largo periodo de completo aislamiento, medida tomada por las autoridades rusas contra la viruela negra y otras epidemias extendidas en las posesiones del Imperio Otomano ${ }^{31}$.

Para concluir sería oportuno subrayar la importancia del viaje de Miranda al Imperio Otomano. Es verdad que tres meses de estancia apretados en cuatro años de viajes no se pueden considerar de importancia primordial. Pero sí valdría la pena recordar que el mismo Miranda expresa que la capital otomana cuenta aproximadamente con un millón de habitantes, cifra abultada en comparación con la población de Moscú de aquellos días, que era de cerca de $250.000^{32}$. Por otra parte, pensamos que no sería muy lógico considerar que el Precursor había pasado por el Imperio Otomano tan sólo porque el camino de Rusia lo había llevado por allí, cuando habría sido mucho más facil tomar rumbo a través de Europa Oriental,

30 MIRANDA, Francisco de: Colombeia ..., p. 443.

31 GRIGULIEVICH LAVRETSKI, José: Miranda, Ediciones de la Contraloría, Caracas, 1974, p. 59.

32 GRIGULIEVICH LAVRETSKI, José: Miranda, Biblioteca de la Academia Nacional de Historia, Caracas, 1991, p. 70. 
sin tener que cruzar el sur de los Balcanes y realizar las travesías marítimas que le llevaron bastante tiempo y le causaron grandes molestias y sinsabores en aquella etapa del año. Entonces tendríamos que buscar una justificación para que Miranda hubiera preferido este rumbo al otro.

La posibilidad de que el Imperio Otomano fuera uno de los destinos a los que el Precursor fuera en busca de apoyo para la causa hispanoamericana tampoco parece ser lógica y además, en prueba de ello, Miranda en Turquía no se entrevista con ningún dirigente de la Sublime Puerta. No hay señales de que siquiera hubiera intentado establecer contacto con algún dirigente cercano a la Puerta. Éntonces tendríamos que atenernos a la idea de que Miranda habría visitado el Imperio Otomano para ver y conocer el sistema socio-político, la economía y, cómo no, la estructura militar del Imperio. Si hubo o no alguna segunda intención detrás de este interés no es muy fácil decirlo con certeza, y pensamos que futuras investigaciones en Rusia e Inglaterra podrían arrojar alguna luz sobre este punto. El imperio de Catalina, con un Miranda o sin él, dispondría de muchos recursos necesarios, tanto materiales como de información o espionaje, como para evaluar el poderío de aquel imperio musulmán que le impedía llegar directamente a las cálidas aguas del Mediterraneo. Además, Rusia a la altura del año 1786 ya había logrado una buena parte de tales objetivos. Si cualquier dato aportado por Miranda ante sus anfitriones rusos hubiera tenido algún valor específico en cambiar una situación dada, será siempre muy difícil precisarlo. Varios historiadores rusos han estudiado a Miranda con mucho detenimiento y ninguno ha determinado la existencia de alguna causa o consecuencia de índole estratégica en la visita otomana de Miranda.

Resultan muy interesantes las impresiones de índole cultural que Miranda recoge tras apreciar, aunque sea parcialmente, el nivel de lectura y ciertos aspectos de la civilización otomana de la época. Me parece oportuno citar el siguiente comentario de la historiadora venezolana, Carmen L. Bohórquez Morán:

«Miranda permanece ocho semanas en Constantinopla observando atentamente todo cuanto le estaba permitido conocer a los extranjeros. Al cabo de su visita llega a la conclusión de que los libros que había comprado con el fin de informarse sobre las costumbres y el carácter del pueblo turco, no le habían servido de nada. Estos libros no señalaban sino los aspectos negativos y omitían citar, por el contrario, las múltiples virtudes de ese pueblo, entre las cuales se encontraban la solidaridad, la lealtad -incluso hacia los extranjeros, una vez establecidas relaciones de amistad o de trabajo- y una dignidad a toda prueba: 'Lo que me hace pensar -dice- que es más fácil formar una nación ilustre de un pueblo bárbaro, mas con carácter y dignidad, que de uno ya envilecido, aunque haya sido tan ilustre como el griego mismo'. Todas estas novedosas experiencias, sin embargo, no le hacen olvidar su ideal y América continúa estando presente en sus conversaciones» ${ }^{33}$.

${ }^{33}$ BOHÓRQUEZ MORÁN, Carmen L.: Francisco de Miranda, Precursor de las Independencias de la América Latina, El Perro y La Rana Ediciones, Caracas, 2006, p. 119. 
Lo cierto es que Francisco de Miranda, tal como se le evaluara y considerara, fue un hombre extraordinario, que se adelantó a su tiempo y se ubicó donde muchos mandatarios de aquel entonces no se atrevían a llegar. Muchos países y muchas culturas podrán reclamar, con autoridad válida, parentesco y relación con sus periplos por la independencia de la América Española. Por ello se le ha conocido como el Precursor. Para Turquía, entonces imperio, cultura y califato a la vez, el venezolano Francisco de Miranda fue el primer latinoamericano célebre en pisar su territorio, tal como Rafael de Nogales Méndez a principios del siglo XX sería el último de ese milenio.

Nunca se terminará de conocer a fondo a un personaje tan especial, tan idealista y tan activo a un mismo tiempo. En Turquía estamos muy atentos a este redescubrimiento y saludamos el que la Embajada de la República Bolivariana de Venezuela en este país lo recuerde con un busto majestuoso que lleva una placa ilustrativa de su arribo a Esmirna (Izmir) en un parque de Ankara, al que la alcaldía de Çankaya le ha conferido el nombre de General Francisco de Miranda Parkı (Parque del General Francisco de Miranda). 